\title{
La primera fábrica de monedas: El Real Ingenio de Segovia
}

\author{
Victoria SOTO CABA *
}

La España del siglo xVı no supo fabricar, según Fernández Álvarez, el sistema económico que precisaba para mantener su fuerza, y el resultado fue la inevitable decadencia de su Imperio ${ }^{1}$. Los preciosos metales indianos, que en formidables remesas llegaron a la península, se derramaron en monedas de oro y plata por la opulenta Europa y éstas, sin embargo, fueron fabricadas por el Estado español en el tránsito que iba desde el puerto de Sevilla a las manos de los banqueros genoveses y comerciantes holandeses.

Aunque la España de los Habsburgo fue uno de los centros de acuñación de moneda más importantes de la época, tan sólo siete cecas existían en la península al inicio del reinado de Felipe II. De origen medieval todas ellas, tuvieron un cierto esplendor y una actividad importante tras la regulación del sistema monetario impuesto por los Reyes Católicos y la prohibición de acuñar moneda por privilegio. Desde entonces y con la intervención o control real, las siete cecas castellanas (Burgos, La Coruña, Toledo, Cuenca, Segovia, Sevilla y la recién fundada de Granada) ${ }^{2}$ contaron con una organización administrativa y una mecánica defi-

- Departamento de Historia del Arte. UNED.

- Fernandez Álvarez, Manuel, La Sociedad Española en el Siglo de Oro. Madrid, Editora Nacional, 1984, pág. 152.

${ }^{2}$ Bartolome, A., y Sainz Varona, F. A., explican gráficamente la evolución y el crecimiento de las cecas medievales según la ampliación del marco geográfico de Castilla, Cfr. Catálogo de la Exposición La Ceca de Burgos. Burgos, Publicaciones del Ayuntamiento de Burgos, 1983. GarCía TAPIA, Nicolás, añade una ceca más, la de Valladolid, de época de Enrique IV y Juan II, ceca itinerante según los traslados de la Corte; Cfr. Técnica y poder en Castilla durante los siglos xvi y xvil. Salamanca 1989, pág. 160. Para la ceca toledana ver la reciente sintesis de Matin-Peñato, M." José, "La Casa de la Moneda de Toledo", Numisma $n .^{\circ} 228, \mathrm{XLI}, 1991$, págs. 99-103. 
nida de operaciones ${ }^{3}$. En cada ceca trabajaban oficiales especializados (ensayador, fundidor, entallador, balanzario...) y obreros no cualificados o monederos. La fórmula de acuñación fue la tradicional. González Tascón asegura que hasta la Baja Edad Media esta actividad permanece manual, a golpe de martillo, y muy similar al trabajo de la forja en la ferrerias. En algunos casos, como la ceca de Burgos, para mover una primitiva maquinaria de mazos se empleó la energía hidráulica a través de una rueda de molino que aprovechaba el curso de un río ${ }^{4}$.

Sin embargo, no es hasta el siglo xVI y, concretamente, hasta el reinado de Felipe II cuando se puede hablar de una nueva solución para la fabricación sistemática de monedas en la península. La nueva fórmula fue el resultado de los progresos alcanzados en Francia y Alemania, una vez solucionado el problema del estiro en láminas de metal con el empleo conjunto de la fuerza hidráulica ${ }^{5}$. La adaptación de este nuevo artificio mecánico o, en palabras de la época, “ingenio", se podría insertar en la denominada renovación científica del siglo XVI que hizo de las cecas un lugar de reactivación técnica de notable relieve. López Piñero mantiene que tal resurgir queda ligado al importante avance que en materia de ensayo de minerales y metales tuvo lugar en España, así como a la necesidad de aplicar técnicas rigurosas para determinar la ley de las monedas y, por último, a los continuos trabajos hidráulicos de los ingenieros de aquella centuria ${ }^{6}$. Sin embargo, frente a la certeza de esta actividad científica y técnica, el nuevo “ingenio" fue, como muy bien define Garcia Tapia, un caso ejemplar de utrasvase o importación de tecnología» al panorama industrial de la España de Felipe $1 \mathrm{I}^{7}$.

La implicación de este monarca en la creación de una nueva ceca en Segovia para acuñar moneda siguiendo el nuevo método extranjero fue recogido por numerosos cronistas de la época. El viajero Enrique Cock indicaba que en 1592 el rey "con los de su casa baxó a veer los edificios y molinos de nueva moneda, que aquí se bate, invención de Alemaña” ${ }^{8}$. Años después, en 1605 , el cortesano portugués Pinheiro da

\footnotetext{
${ }^{3}$ Crr. SurRa Y Rull, Juan, Breve reseña histórica de la organización y régimen de las Casas de Moneda de España. Madrid, Establecimiento tipográfico de T. Fortanet, 1869.

${ }^{4}$ Cfr. Gonzalez Tascón, Ignacio, Fábricas Hidráulicas Españolas. Madrid, Ministerio de Obras Públicas, 1987, pág. 109.

${ }^{5}$ Para el tema en particular ver DURAN, Rafael, "La acuñación del molino de la ceca de Segovia". Numisma, núm. 14, V, 1955, págs. 119-158.

- Lopez Piñero, José María, Ciencia y Técnica en la Sociedad Española de los siglos xvI y XVII. Barcelona, Läbor, 1979.

7 Garcia Tapia, ob. cit., pág. 159.

- Cock, Enrique, Jornada de Tarazona hecha por Felipe II en 1592 pasando por Segovia. Madrid, Imprenta y Fundición de M. Tello, 1879, pág. 9.
} 
Veiga dejó una breve descripción del ingenio "con ruedas hidráulicas, cosa increible, aún después que se ve, y la facilidad y presteza con que se hace" ${ }^{9}$. La admiración que producía este artilugio fue también comentado como "digno de alabanza" por Agustín de Rojas Villandrando ${ }^{10}$. Pero fue Diego de Colmenares en su Historia de la Insigne Ciudad de Segovia " ${ }^{11}$ el primero en poner de relieve el interés que en esta nueva casa de moneda puso Felipe $\mid \mathrm{y}$ y los avatares de la instalación del ingenio.

Las continuadas investigaciones de archivo que sobre este tema se han venido realizando permiten un mejor conocimiento de lo que fue uno de los primeros edificios industriales de la España del Renacimiento. García Tapia a través de la documentación consultada en el Archivo General de Simancas resume las diversas fases de la construcción de la fábrica, así como los complejos factores que empujaron al monarca a realizar un espectacular traslado por tierra y por mar de maquinaria desde Innsbruck hasta Segovia, incluyendo en ello a un grupo de especialistas e ingenieros centroeuropeos y, por último, las razones que le llevaron a elegir el nuevo emplazamiento segoviano. En este sentido, cabe decir que la instalación del «ingenio" fue la respuesta al acuciante problema económico que atravesaba el reinado filipino: subrayando la necesidad de atender a las guerras de los Países Bajos, la preparación de la Armada Invencible, la febril construcción de palacios, jardines y diversos edificios por parte del monarca, asi como los absorbentes gastos de la Corte ${ }^{12}$.

La elección de Segovia ya fue, sin embargo, analizada por diversos historiadores: su tradición artesanal e industrial, la abundancia de molinos de papel y harineros en las orillas del río Eresma y, sobre todo, la existencia de una ceca en la ciudad con el consiguiente colectivo de monederos hizo descartar una primera idea de situar la ceca en Madrid, - «no hallando disposición en el río por la poca aguas ${ }^{13}$, eligiéndose otra ciudad que contaba con la ventaja de estar próxima a la Corte ${ }^{14}$.

9 Pinheiro da Veiga, Tomé, Fastiginia o Fastos Geniales. Valladolid, Imprenta del Colegio de Santiago, 1916.

10 En El Viaje Entretenido (1604). Madrid, Espasa-Calpe, 1977, vol. II, pág. 73.

"Segovia, Por Diego Díaz Impressor, 1637.

12 Garcia Tapia, Nicolás, ob. cit, pág. 155.

13 Colmenares. Diego de, ob cit, pág. 577.

14 Cfr. Lecea y Garcia, Carlos, Recuerdos de la antigua industria segoviana. Segovia, Imprenta Santiaste, 1897; Rivero, Casto María del, Segovia Numismática. Estudio General de la Ceca y de las monedas de esta ciudad. Segovia 1928; Hernandez RUIz dE VILLA, Rafael, "Notas sobre la Real Casa de la Moneda de Segovia, hasta la Guerra de la Independencia", Estudios Segovianos, 1965, t. VII, núms. 49-50, págs. 369-38?. El papel de esta ciudad en la acuñación de moneda durante la Baja Edad Media se constata en el 
Uno de los hechos que mayor transcedencia da a esta ceca es la segura intervención en el proyecto del edificio de Juan de Herrera. Casto María del Rivero consideró que la traza y dirección del Ingenio como obra del arquitecto real era un supuesto tradicional desprovisto de todo apoyo documental ${ }^{15}$, remitiendo a la obra de Llaguno, única autorizada para asegurar la intervención de Francisco de Mora en aquella obra ${ }^{16}$. Comprobado, a través de los documentos de archivo, que Juan de Herrera estuvo al mando de la nueva empresa constructiva ${ }^{17}$ en los primeros años y que elaboró una traza para el nuevo edificio, resulta inevitable plantearse el alcance del cometido de este arquitecto, para entonces director de la Academia de Matemáticas y experto ingeniero en temas de maquinaria.

Si bien es cierto, como indica García Tapia, que la construcción del edificio resulta compleja, ya que hay que distinguir las obras de ingenieria hidráulica, la construcción e instalación de los ingenios y las obras de arquitectura en continua modificación, es evidente que todo el conjunto, pero esencialmente la parte arquitectónica, suponía para la máxima figura del Renacimiento español la resolución por primera vez de un problema tipológico ligado a la arquitectura industrial y en concreto a la de un edificio para la fabricación de moneda. Edificio cuya idea debía ser ajena, por lógica, a aquella que imperaba en las siete cecas restantes de la península.

Apenas se conoce cuales eran las características y distribución de estas últimas durante los años en que se construye el Ingenio de Segovia. Es de suponer que presentarán la típica estructura del molino tardo-

documento publicado en Estudios Segovianos, t. XXIII, núm. 67, 1971, págs. 140-151, sobre los privilegios dados a los monederos de la Casa de Segovia desde Enrique IV.

15 Rivero, Casto María del, "El Ingenio de la Moneda de Segovia. Monografía numismática", Revista de Archivos, Bibliotecas y Museos. Madrid 1919, págs. 7 y siguientes.

${ }^{16}$ Llaguna y Amirola, Eugenio, Noticia de los Arquitectos y de la Arquitectura en España. Madrid, Imprenta Real, 1829 ; en el tomo III, págs. 125-126 y 344, la referida intervención del discipulo de Juan de Herrera.

17 Además del trabajo citado de GaRcía TAPIA, hay que contar con la exhaustiva investigación que desde hace años viene realizando el historiador y numismático MURRAY, Gleen S., probablemente la persona que en la actualidad mayores conocimientos tenga sobre la Casa y el Ingenio de la Moneda de Segovia. Quiero agradecerle el que me haya permitido consultar la documentación recogida en el Archivo General de Simancas; La fundación del Real Ingenio de la Moneda de Segovia. Desde los primeros indicios hasta sus primeras monedas (1575-1586) visto a través de 43 documentos del Archivo General de Simancas (en prensa). Muy recientemente todos los prolegómenos en relación a la instalación de esta ceca han sido cuidadosamente analizados por este autor y GOMEZ NIETO, Leonor, "Génesis del Real Ingenio de la Moneda de Segovia. I. La Idea (1574-1582)", Numisma, $n .^{\circ} 228, \mathrm{XLI}$, 1991, págs. $59-80$. 
medieval, como el caso referido de la de Burgos, o bien que se utilizara un edificio preexistente como ocurrió con la de Granada. Garzón Pareja señala que, al ser fundada tras la conquista de la ciudad por los Reyes Católicos, la nueva fábrica se instaló en el Maristán, antiguo hospital de locos edificado por Mohamed $V$ entre 1365 y 1367. Se trataba de un edificio en torno a un gran patio alargado con alberca central, de dos pisos de galerías sobre pilares y largas salas en los cuatro testeros ${ }^{18}$. García Tapia refiere las vicisitudes de la ceca vallisoletana, mencionando tan solo su localización en la ciudad. Fundada por Felipe II en 1568, fue levantada entre 1569 y 1571 y reconstruida tras una crecida del río $\mathrm{Pi}$ suerga, en $1583^{19}$. Esta clase de avatares, asi como los numerosos incendios producidos por los hornos, jalonan la historia de las cecas, originando infinidad de reparaciones y continuas reconstrucciones. Quizá, por esto, este tipo de fábrica adoleció a lo largo del período barroco de una configuración arquitectónica imprecisa.

Podría decirse, por tanto, que cuando Juan de Herrera recibe el encargo de proyectar una nueva ceca en Segovia partía de cero, ante la ausencia de cualquier ejemplo fabril normalizado en la peninsula, y con todas las posibilidades de codificar un tipo de fábrica para los nuevos avances técnicos de acuñación. Es cierto que al arquitecto le impusieron una serie de cortapisas inevitables: realizar la traza del edificio reutilizando un antiguo molino de papel que existía a orillas del río Eresma, muy cercano al Monasterio del Parral, proyecto que debía seguir las indicaciones de los ingenieros llegados de Innsbruck. También es cierto que la documentación de archivo no niega desavenencias entre el arquitecto real y los oficiales alemanes, pero quizá se haya dado excesiva importancia a ciertas dificultades más inmersas en el celo profesional de una figura que era, en aquellos momentos, el primer arquitecto del rey, un rencmbrado ingeniero con sobrados conocimientos en máquinas y capaz, por ello, de entender la compleja adaptación que requería el ingenio importado *.

No hay que olvidar que en materia hidráulica la España de la segunda mitad del siglo XVI había experimentado avances importantes, gracias sobre todo a la política constructiva de Felipe II. Incluso ya existían tra-

is Garzón Pareja, Manuel, La Real Casa de la Moneda de Granada. Granada, Publicaciones del Archivo de la Real Chancillería de Granada, MCMLXX, pág. 4.

19 GaRCia TAPIA, Nicolás, ob. cit. págs. 162-163.

* Sería ocioso intentar remitirnos a una selección bibliográfica sobre el arquitecto. No obstante resulta inevitable mencionar los trabajos de Ruiz Arcante, Cervera Vera o el Catálogo de Herrera y el Clasicismo, entre otros muchos. 
tadistas sobre el tema. Aunque manuscrito, Pedro Juan de Lastanosa deja el primer estudio sistemático de hidráulica en Los veintiun libros de los ingenios y las máquinas, tratado escrito más de diez años antes a las obras de la ceca segoviana ${ }^{20}$. Anterior también fue la recopilación de molinos de Francisco Lobato del Canto. Juan de Herrera por su parte contaba en su biblioteca con un ejemplar manuscrito de la Declaración del uso y fábrica de instrumentos de agua, molinos y otras cosas, de Jerónimo Givara, así como la experiencia de sus ingenios hidráulicos para las cocinas y lavaderos de El Escorial, en 1567, amén de la atribución de la Fuente Nueva de Ocaña, un complejo sistema de captación de aguas iniciado en $1574^{21}$.

Quizá aquellas "desavenencias" provinieran de la desconfianza del arquitecto hacia los inventores de "ingenios", "cosas imposibles y no concedidas de la natura", que se acercaban a la Corte, aspecto que ya recogió Eugenio Llaguno y que muy bien subraya García Tapia ${ }^{22}$.

Por otro lado, la búsqueda de un lugar apropiado para la instalación no fue fácil. Desde que el archiduque Fernando de Austria ofrece el nuevo tipo de máquina al monarca español en 1580 hasta que se encuentra el molino en junio de 1583, pasan tres años de búsquedas por diversas ciudades de la península. Uno de los documentos recogidos por Murray es una relación de gastos realizada por Filiberto Zomere «para entretener los alemanes monederos", en el que consta su estancia en Madrid, la ida a Lisboa, un posterior viaje a Sevilla, la vuelta a Madrid y estancia en Segovia y Toledo ${ }^{23}$. Aunque García Tapia indica que en septiembre de 1582 se compraba el molino segoviano, todavía en abril de 1583 no se había decidido el nuevo emplazamiento, ya que Juan de Herrera ordenaba al maestro alemán Wolfgang Ritter ir a Toledo «a ver que disposición avrá allí para poder hazer algún Ingenio» ${ }^{24}$.

El hallazgo del sitio se produce a comienzos del verano de aquel mismo año: "se ha hallado en Segovia un molino de papel muy a propósito para su obra» ${ }^{25}$. Inmediatamente debió realizarse la compra del molino, propiedad de Antonio de San Millán, y de los terrenos colindantes

${ }^{20}$ El manuscrito ha sido publicado por J. A. Garcia Diego, Madrid 1983.

${ }^{21}$ Cfr. Garcia TAPIA, N., Ingenieria y Arquitectura en el Renacimiento Español. Valladolid, Secretariado de Publicaciones, 1990.

22 Cfr. Llaguno, Eugenio, ob. cit, tomo II, pág. 336. 256).

${ }^{23}$ S. Murray, Gleen, ob. cit., Documento núm. 9 (A.G.S., Guerra Antigua, leg. 147, fol.

${ }^{24}$ Idem, leg. 144 , fol. 111.

${ }^{25}$ Idem, Documento núm. 14, leg. 146, fol. 131. 
a la orilla izquierda del rio Eresma, propiedad del obispado de Segovia. El terreno estaba situado "baxo de la iglesia de Santiago que confina con el molino de papel a la puente del parral..." y el molino lindaba con varias calles públicas y "con el mismo río Heresma por donse se gobierna el dicho molino con su presa" ${ }^{26}$. El molino, con su huerta y cercas, fue adquirido a su dueño por 10.000 ducados ${ }^{27}$.

Tras la compra los preparativos de la nueva ceca se suceden con rapidez. En agosto la ciudad de Segovia ofrecia al monarca la madera del pinar de Balsain para la futura construcción ${ }^{28}$ y en octubre Juan de Herrera se trasladaba al lugar para coordinar la obra con los alemanes: "aunque con harta dificultad se concertaron en la manera del edificio y se hizo su planta" ${ }^{29}$. A pesar de ello, Juan de Herrera escribía desde El Escorial a Antonio de Eraso, "Secretario de Su Majestad", asegurando que todo "quedó resuelto como mejor combenía y pasreció y de todo aquello se sacó una traça que traygo conmigo para quando se tratara de algo de esto...". Añadia que había dado orden al veedor "para que luego les haga una fragua y la memoria de alguna madera que será menester para el nuevo edificio, aunque los alemanes an de dar otra [memoria] de la que será menester para los ingenios". Por último, señalaba que había dado una "traça a un official de canteria de lo tocante a lo que de ella mampostería se a de hazer en la fábrica nueva y canal de los ingenios" $"$ 30.

En el mismo documento se solicitaba ya el dinero para llevar a cabo la obra - «lo que resta agora es que vuestra merced les mande imbiar dineros...»-, petición que volverá a reiterarse desde Segovia, cuando en noviembre "ya se ha començado a derribar el molino..." y estaba a la espera de recibir "los Ingenios porque haze mucho al caso el estar aqui para acabar de todo punto la fábrica» ${ }^{31}$.

Nada se sabe de estas dos trazas que realizó Herrera, la que llevó

${ }^{26}$ De la documentación del Archivo del Ayuntamiento de Segovia, recogida por Ruiz Hernando, Antonio, Historia del urbanismo en la ciudad de Segovia del siglo xil al xix. Segovia 1982, tomo I, pág. 147.

${ }^{27}$ Dato que aparece ya en las obras citadas de Colmenares, Diego de, y Rivero, Casto María del, y corroborado por la documentación recogida por MURRAY, A.G.S. fol. 158).

28 S. MurRaY, Gleen, ob. cit. Documento núm. 18 (A.G.S., Guerra Antigua, Leg. 148,

29 Idem, Documento núm. 19, leg. 159, fol. 372.

30 La totocopia de este documento me ha sido proporcionado por Alicia Cámara, A.G.S., Guerra Antigua, leg. 151, fol. 7.

${ }^{31}$ S. Murrar, Gleen, ob. cit., Documento núm. 21, (A.G.S., Guerra Antigua, leg. 151, fol. 36). 
a El Escorial y la que dejó en Segovia para el maestro de canteria, y que impiden una clara comprensión del nuevo proyecto, ya que por los documentos la obra arquitectónica queda siempre engarzada con la parte hidráulica del molino y la zona de gobierno de los ingenios. La imagen gráfica conservada, un rasguño y una traza de Gómez de Mora, pertenecen a un período posterior, cuando la fábrica había sido remodelada en más de una ocasión. Las continuas reformas que hasta comienzos del siglo $x x$ sufrió el edificio tan sólo permiten asegurar la conservación de los muros y de la estructura externa ${ }^{32}$.

En el proyecto de Herrera el perímetro de la nueva casa "tiene de quedar de çien pies de largo y treynta de ancho". Conllevaba pues un planteamiento espacioso. Se eliminaron los "colgadizos" y otros estorbos anejos al molino. De éste se conservaron elementos hidráulicos, ruedas y mazos que, como indica García Tapia, pudieron aprovecharse para la nueva instalación.

Por otro lado, hay que contar con la existencia de un segundo molino, que siguió funcionando como fábrica de harina y papel, y que en los documentos se menciona como "molino o cassa vieja".

Las obras se realizaron con gran rapidez hasta abril de 1584, momento en que el deshielo y la crecida del Eresma paralizaron las obras. Desde el comienzo, la proximidad del agua originaba serios inconvenientes: "Los çimientos es lo más difiqultoso por andar tan beçinos del rrío". También lo fue el desnivel del terreno, desigual y accidentado, que obligó a realizar un muro de contención frente a la nueva casa.

Pero, para la fecha indicada, el arquitecto real ya habia dejado la dirección de la obra en manos del veedor, Francisco de Ribera, junto a Diego de Matienzo, maestro de cantería, y Juan de Minjares, aparejador encargado de la obra en madera. Las nuevas referencias a la marcha de las obras proceden de los informes de éstos y la ausencia de Herrera indica más que nada su papel albertiano en el diseño de la obra. Su control no desapareció, puesto que en mayo de 1584 Francisco de Ribera escribía que había llevado «en una montea el estado en que esta

32 La administración del Real Ingenio de la Moneda si que contaba con planos del edificio, ya que cuando en 1869 se decreta la suspensión de esta ceca, la Dirección General del Tesoro público ordenó enviar "todos los efectos de dicha casa a la Casa de Moneda de Madrid". Para ello se realizó un inventario en el que se menciona la llegada de "planos de la fábrica de Segovia" entre otro documentos. «Inventario de los papeles recibidos en esta Casa de Moneda, procedentes de la de Segovia", Archivo Histórico Nacional, Fondos Contemporáneos, Hacienda-Casa Moneda, leg. 7.372 (1). A pesar de nuestra búsqueda, no hemos hallado dichos planos. 
la obra del yngenio para que partiqularmente la biese la magestad del rrey nuestro señor y por estar su magestad con un poco de mala dispusiçion de la gota no lo pudo al presente ver y la dexe a Juan de Herrera el estado en al presente está la obra por todos lados es 15 pies de alto con todas puertas y ventanas elegidas en la orden baxa de la casa y a la pared que tiene de yr entre ella y el rrio que con lo que tiene de entrar por el molino y pasar el rrio abajo..." ${ }^{33}$.

El edificio entonces contaba con las cuatro paredes y se habian iniciado "seys aposentos", acarreándose gran cantidad de piedra y madera de los vecinos bosques de la zona. Se encargaban además a talleres segovianos y del país vasco doce rejas que darían seguridad al edificio. En junio de 1584 la fábrica «iba por algunas partes de la segunda orden". La distribución de los vanos ya estaba resuelta: "Las bentanas bajas son doze y otras tantas las altas al nibel de las bajas esto es a la parte del mediodia, porque al çierço en el suelo alto no a de aber más de seis bentanas en cada aposento la suya y en el baxo de esta parte del çierço y del rrio no ay mas bentanas de una para mirar la rruedas y los aujeros por do an de salir los axes de ellas ${ }^{34}$.

A finales del verano la obra estaba prácticamente concluida. En agosto un informe de Francisco Ribera aseguraba que "le falta muy poquito para subir hasta donde se a de poner la cornixa" y añadía los trabajos que se realizaban de la parte hidráulica. Según Garcia Tapia, éstos se resumen en la instalación de las ruedas de sus ejes traspasando la pared de la casa vieja por tres orificios - - utienese de romper agora la cassa bieja por tres partes para passar por alli la canal de madera que a de rrecebir el rrio"- y un nuevo arco en el puente para desviar el agua a tráves de un canal que al llegar a dicha casa se dividia en tres brazos que alimentarían las tres ruedas - «la cassa bieja que era molino se a rrecebido sobrepuntales de muy gruessas bigas para poner alli la canal grande de madera que rreçibe toda el agua del gobierno de las rruedas y de donde se tiene de rrepartir a cada partiqular»- ${ }^{35}$.

Un mes después se añadió un pequeño edificio: «una ofiçina para el carbon se a hecho arrimada a la casa y por la arquitectura della sin diferençiar con 6 bentanas tiene toda la cassa al largo 136 pies alemanes

33 S. Murray, Gleen, ob. cit, Documento 26, (A.G.S., Guerra Antigua, leg. 162. tol. 174).

${ }^{34}$ idem, Documento número 27, leg. 163 , fol. 18.

${ }^{35}$ Garcia Tapia, Nicolás, Técnica y Poder en Castilla..., ob. cit., pág. 146 y S. Murray, Gleen, $a b$. cit., Documento núms. 29 y 30; (A.G.S., Guerra Antigua, leg. 165, fol. 46). 
que son 150 ". Dejando bien patente esta continuidad en el estilo arquitectónico, Ribera añadia "que si su magestad fuere serbido después mandar que sea el texado de piçarra no aya que mudar en el ninguna madera yo ire a Madrid... y llebare a vuestra merced el modelo de como ba el tejado y la orden de como hago hazer las rrejas" ${ }^{36}$.

A lo largo de todos estos informes el veedor de las obras no cesaba de reclamar el dinero para pagar a los alemanes como para comprar los materiales y todavía en diciembre, cuando ya estaba concluida la fábrica y la presa del río, solicitaba "dineros para pagar hierro, clabazones y rrejas".

En 1585 se documenta ya la llegada de «mucha plata al ingenio", asi como una serie de reformas "para aposento de los alemanes postreros y para ensanchar un poco el aposento del teniente tesorero del señor conde y do está el platero" ${ }^{37}$. Se construye un muro de contención a lo largo del río para evitar la inundaciones producidas por la sobreelevación de la presa. Un año después llegaban nuevos ingenieros alemanes para acoplar las máquinas del ingenio y el 27 de marzo se realiza la primera prueba de acuñación. Por último, en 1507, el monarca manda librar 400 ducados para hacer una fuente que todavía se conserva.

Hasta aqui se sintetiza lo que fue la construcción de uno de los más antiguos monumentos de arquitectura industrial europea, en palabras de Georges Kubler. Continuaron trabajos de mantenimiento y reparación durante los últimos años del siglo, pero se puede decir que en 1587 el edificio ya estaba totalmente acabado y su fábrica en funcionamiento. Era justo el año en que muere el arquitecto Juan de Herrera, el autor de la traza, aunque la responsabilidad material recayera en Francisco de Ribera y Juan de Minjares. Los contactos del arquitecto con el proceso constructivo parecen bien escasos: un reconocimiento del terreno y de un viejo molino, una puesta en común con los especialistas alemanes, una traza compleja para readaptar el antiguo molino y una visita al comienzo de las obras. En definitiva, un control lógico en un arquitecto demasiado atareado en otras arquitectónicas de mayor envergadura. No obstante, la casa de moneda o Real Ingenio de Segovia no era una empresa de carácter menor, más bien podria decirse que era un proyecto arquitectónico de vital importancia: el lugar donde se sanearía la economia española. García Tapia, en este sentido, comenta como la ceca se fol. 5)

${ }^{36}$ S. Murray, Gleen, $o b$. cit, Documento núm. 31, (A.G.S., Guerra Antigua, leg. 167,

${ }^{37}$ Idem, Documento núm. 38, leg. 179, fol. 329. 
construye en los momentos más álgidos de la política arquitectónica filipina. Se necesitaba dinero para continuar y terminar las obras emprendidas y el edificio segoviano sería el regenerador de aquella política. De ahí se explica la prisa en terminar las obras, algo parelelo a la característica de casi todas las empresas iniciadas por Felipe II.

El interés del rey por este «lugar de acuñar dineros» no presupone, por los documentos, una atención especial, una inclinación hacia el proyecto estético. Los informes revelan una aceleración constante en la marcha de las obras que apuntan al objetivo material que iba a tener la fábrica. Sin embargo, el riguroso control con que el monarca dirigió los más mínimos detalles de su política también quedan plasmados en los informes que rinde Francisco de Ribera, tanto a palacio como a Juan de Herrera, al presentarles una montea de cómo iba la obra, indicar la disposicón de los vanos, preguntar la conveniencia de poner pizarra en los tejados y llevar un modelo de estos últimos. Desde este punto de vista, la dirección del arquitecto real está clara, en cuanto que Ribera parece seguir las indicaciones del proyecto al pie de la letra.

Una obra de estas características, que conjuga arquitectura, técnica e ingeniería, no debió ser un simple apunte o un mero ejercicio para Herrera, aunque no tuviera parangón con las obras que dirigia en la corte. Por primera vez, se trataba de un proyecto de fábrica a enfrentar con las viejas cecas de un país que debía convertirse en exportador monetario. Herrera fue, pues, consciente del anómalo arcaísmo que presentaban áquellas.

Fiel a su estilo, planteó la más austera y sencilla solución a la nueva fábrica arquitectónica: un largo bloque rectangular de dos pisos, cuyos paramentos niegan cualquier concesión al recreo y se ciñen al ritmo de 24 ventanas, de molduración rígida, en su fachada principal, divididas y dispuestas simétricamente en los dos órdenes. Los añadidos de la carbonera y de la ampliación de los aposentos no debieron alterar este ritmo, por lo que se deduce del informe de Francisco de Ribera. Al norte el edificio quedaba engarzado con lo que quedó del antiguo molino a través de los canales, las ruedas y el complejo técnico e hidraúlico (fig. 1).

El añadido que se hizo a comienzos del siglo $x x$ de un piso en el tramo central de la fábrica alteró por completo su silueta, aunque todavía se conservan gran parte de los recubrimientos de pizarra (fig. 2). Para Ruiz Hernando este material fue una novedad importante en la arquitectura segoviana ya que supuso un cambio en la tradicional forma de cubrir 


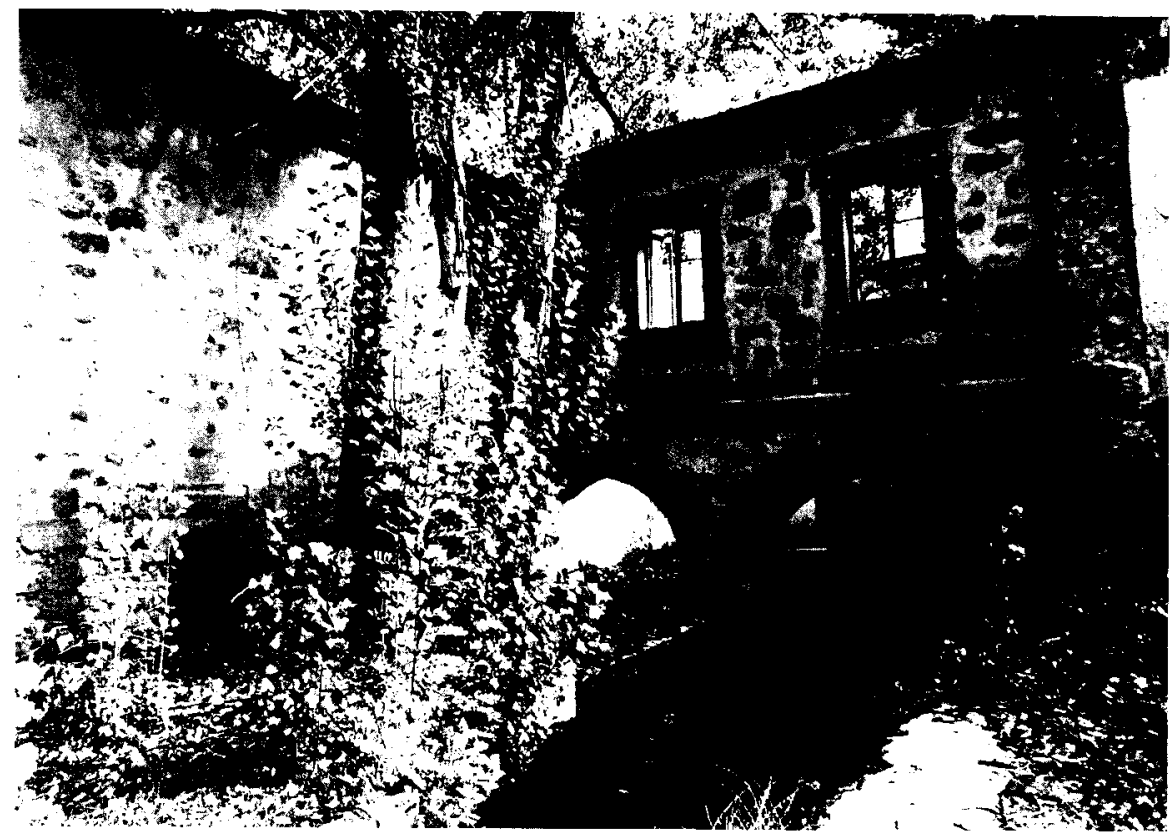

Fig 1 Estado aciual del canal del Real Ingenio de Segovia

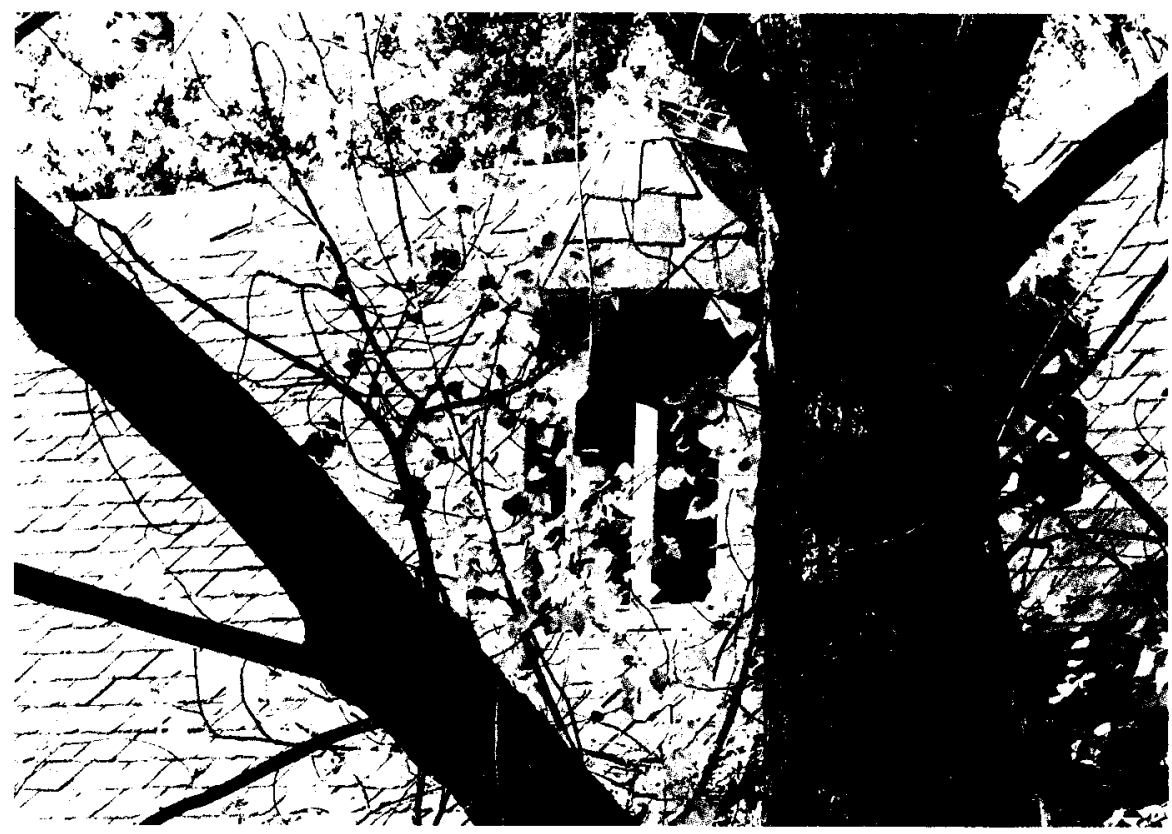

Fig. 2. Tejado y cubrimientos de pizarra de la fabrica de moneda de Segovia. 


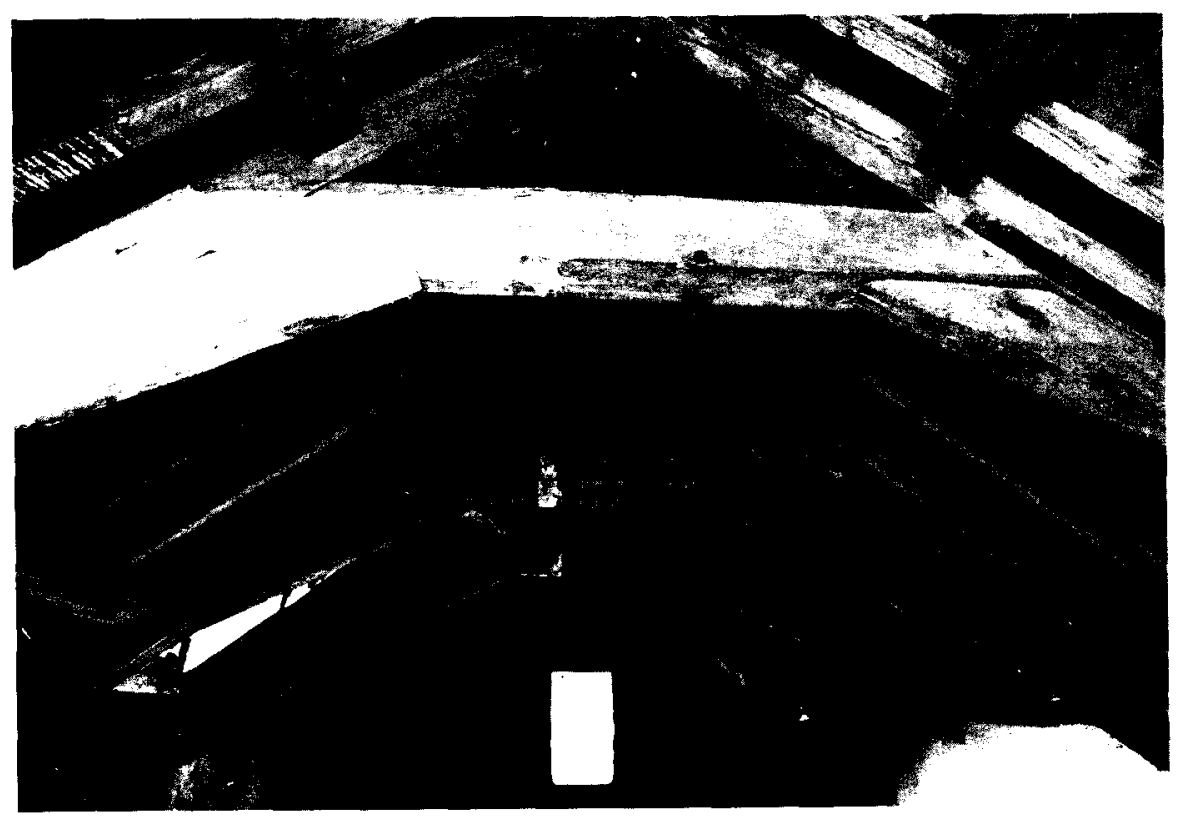

Fig. 3. Interior de las cubiertas de la fábrica de moneda.

con teja árabe, indicando que «vino a ser el contrapunto del alcázar, que por aquellas fechas también se empizarró" ${ }^{38}$.

La complejidad de la obra y la falta de planos y trazas dificultan cualquier hipótesis acerca de su configuración interna. Podría conjeturarse que la planta baja estaría dedicada por entero a estancias fabriles y que el segundo piso albergaría, en la zona norte, los seis aposentos correspondientes a las seis ventanas que daban "al çierço y al río". Las sucesivas reformas debieron alterar los cubrimientos interiores que, a pesar de la enorme cantidad de madera empleada en el ingenio - la mayoria de las cubiertas fueron realizadas en madera (fig. 3)-, debieron tener posiblemente y al menos en algunas estancias cierres de bóveda vaidas de ladrillo, característica que aparece en otros proyectos ingenieriles del arquitecto.

Si bien la mayor parte de tales conjeturas quedan a merced de deducciones extraídas de los documentos posteriores, de época de Mora,

${ }^{38}$ Ruiz Hernando, J. Antonio, ob. cit., pág. 133. 
el interés de esta fábrica no radica tanto en su posible disposición como en si planteó, por ser la primera de nueva planta, una "normalización» arquitectónica para las futuras cecas peninsulares.

Resulta difícil proponer una respuesta positiva, aunque si existió desde el punto de vista legal una clara afirmación del monarca cuando en 1592 dicta unas ordenanzas para el gobierno de la Casa de la Moneda. Con ello se trataba de regular los cargos de los trabajadores, así como la inspección de las fábricas. Se concedió al Superintendente la máxima competencia y jurisdicción civil y criminal y se amplió la plantilla contando desde entonces con un Tesorero, Teniente, Escribano, Ensayador, Maestro de Balanza y Alcalde ${ }^{39}$. Esta regulación debía servir además para corregir los abusos e irregularidades en el proceso de acuñación, algo que venía preocupando al monarca desde la puesta en marcha del Ingenio, ya que en 1588 acordó unas adiciones a las antiguas ordenanzas de sus antepasados que comprendían un tratado completo de ensayes del conocido Juan de Arfe y Villafañe, quien posteriormente será nombrado ensayador de la fábrica segoviana.

Las ordenanzas al menos ofrecen el especial carácter de una ceca: un lugar en el que las entradas y salidas debian ser centralizadas y controladas. Las falsificaciones y los hurtos, como el robo de plata de 1596 en el ingenio, obligaron a tomar medidas que claramente afectaron al edificio: incorporación de nuevas rejas en las ventanas, cerrar los huecos de los ejes de las ruedas hidráulicas... El aumento de la plantilla, a la que hay que añadir los monederos y diez oficiales encargados del mantenimiento y puesta a punto del ingenio alemán, supuso no sólo la ampliación sino también la multiplicación de oficinas y aposentos para albergar a todos aquellos cargos y oficiales que debían residir en la fábrica.

La actual situación y según la planta realizada por Rafael Durán reflejan el crecimiento de la fábrica a base de añadidos a lo largo de los siglos XVII y XVIII: se trata de una agrupación de edificios que fueron cerrándose en torno a un espacio trapezoidal, con lo que se controlaba mejor las entradas al edificio, en cuyo centro se sitúa el muro de contención. Éste salva el desnivel de todo el solar y lo divide en el patio alto y patio bajo.

Al margen de los continuos reparos y reformas que sufre el Ingenio desde 1597, año en que el nombre de Francisco de Mora aparece en los

${ }^{39}$ Cfr. Larruga, Eugenio, Memorias políticas y económicas sobre los frutos, comercio, fábricas y minas de España. Madrid 1787-1800, tomo XI, pág. 172. 
documentos, hay que contar con las sucesivas ampliaciones. La fábrica parece haberse quedado pequeña desde sus inicios a juzgar por las nuevas trazas ${ }^{40}$ de aquél y las compras de edificios colindantes, como un taller para almacenar madera en $1600^{41}$.

Sin embargo, creemos que la intervención de Mora debió ser anterior a la fecha señalada y mucho más radical. Eugenio Llaguno al transcribir los documentos sobre Francisco de Mora mencionaba la existencia de una certificación firmada por el arquitecto "en que aseguraba que todas las obras modernas hechas en el alcázar y casa de moneda se hicieron por traza é ideas suyas y mandado de S. M.", así como una relación del veedor Francisco de Ribera ratificando dichos trabajos ${ }^{42}$. Ello explica que Llaguno no dudara en dar la atribución a Mora, pero también indica que las "obras modernas hechas en el alcázar y casa de la moneda" se empezaron en 1587. Se trata, pues, de un proceso de reedificación puesto en marcha una vez acabada la obra y a la par que la fábrica aumentaba su plantilla y su ritmo productivo, necesitando los mantenimientos y reformas oportunos a cargo del sucesor de Herrera.

Mora realizó reformas en el edificio y en la parte hidráulica al menos en tres ocasiones y hasta 1607, año en que un incendio arruina las techumbres de la fundición. Se ha supuesto que el rasguño sin fecha y sin firma que representa la ceca segoviana fue realizado por Francisco de Mora a raíz de este suceso (fig. 4) ${ }^{43}$. El escueto dibujo, el primero que se conoce de la fábrica, resulta demasiado abstracto como para otorgarle cierta fiabilidad, ya que si bien se trazó para iniciar los reparos tras el incendio, no refleja en alzado la doble altura que debia tener la construcción herreriana. Sin embargo, la planta recoge la distribución interna de la fábrica con sus oficinas. La reforma supuso la construcción de bóvedas de ladrillo y el aumento de la altura de la salida de fundición. Lo más equívoco del gráfico de Mora es la existencia de las oficinas de ensaye, libranza y tesoro dispuestas en sentido perpendicular al bloque arquitectónico primitivo. Tan sólo se puede deducir que o bien el edificio se amplió por el lado oeste después del incendio o bien a raiz de las ordenanzas de 1592. La documentación no aclara este punto, pero es evidente que la traza de Mora corresponde a un edificio anexo, pero ajeno, a la fábrica herreriana.

${ }^{40}$ Según los documentos en Gleen S. Murray, ob. cit., A.G.S., Casas y Sitios Reales, Leg. 267.

a1 Idem, Leg. 322, fol. 72 .

${ }^{42}$ Llaguno, E., ob. cit., vol. III, pág. 344.

${ }_{43}$ A.G.S., M.P y D., XXXIV-22. 

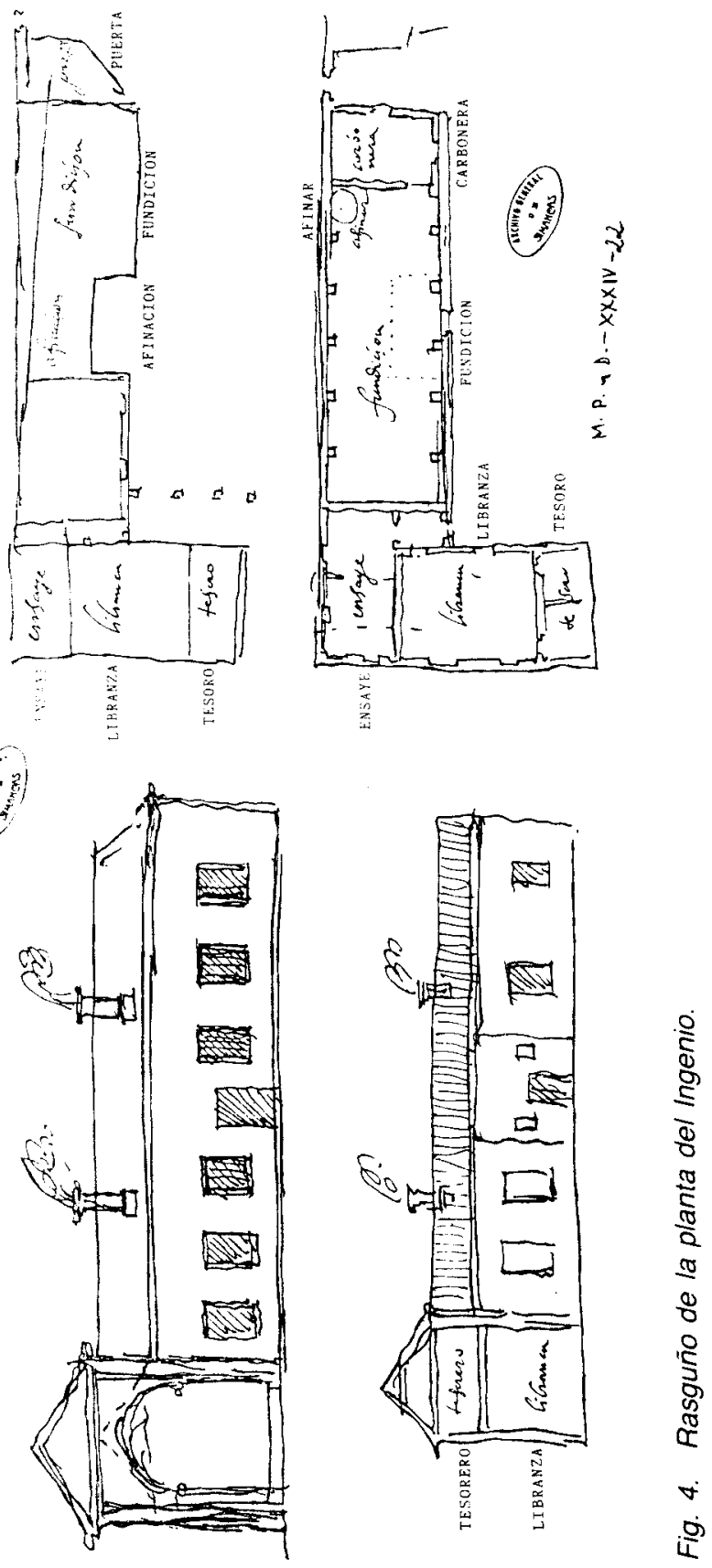
El crecimiento y los añadidos de oficinas se suceden en los años inmediatos. Casto María del Rivero recogió una información al respecto sobre la vivienda del tallador en 1613: «bastatisima bibienda y tanto que Francisco Mora la traço y hiço" ${ }^{44}$. Pero será en 1616 cuando los edificios anexos al ingenio proliferen. De esta fecha data el mandato real para que vivan en el Ingenio todos los oficiales del y conviviendo asi a su Rl. servicio, por lo que importa su ordinaria asistencia a tener el Ingenio bien reparado y conservado" ${ }^{45}$. Para la distribución de los oficiales el aparejador real Pedro de Brizuela ${ }^{46}$ realizó una planta, hoy desconocida. Queda, sin embargo, la Relación de como se han de acomodar..., según la cual se mencionan más de 12 aposentos, algunos de ellos dentro de las salas de fabricación, sin contar los desvanes y la portería para repartir entre oficiales mayores y menores.

Los avatares y las reiteradas intervenciones en el Real Ingenio durante todo el siglo XVII parecen documentar la fragilidad y el deterioro de los mecanismos importados, asi como los problemas que un edificio de estas características comportaba, al estar incorporado a todo un complejo hidráulico, y sobre todo refleja la incapacidad técnica que sufre aquella centuria.

Tanto García Tapia como Gutiérrez Tascón han creído que el único plano de la fábrica se hizo con motivo de una remodelación en 1628. Pero esta última fue una de las tantas realizadas durante el siglo. Gleen S. Murray ha constatado la posterioridad de la planta al coincidir con un documento de 1678: Condiciones para los reparos que han de hacer en la casa del Ingenio... ${ }^{47}$.

La traza lleva la firma de José Vallejo de Vivanco, "aparejador de RIs. Obras", y refleja la distribución y maquinaria del ingenio, como el canal, las ruedas o la fragua. Por las leyendas insertas en el plano se puede deducir que la reforma estuvo dirigida a reparar las instalaciones técnicas que presentaban grandes deficiencias. Las medidas en pies que ofrece el documento citado coinciden con las del plano (fig. 5): “...las tres salas como son sala de acuñar, sala de ruedas y de la fragua, ...que la una tiene 80 pies, y la otra 50 y la otra 60 y su ancho de cada una es

44 Rivero, Casto M. del, El Ingenio de la Moneda..., ob. cit., pág. 8.

${ }^{45}$ Documento recogido por Gleen S. Murray, A.G.S., C. y S. R., leg. 364.

46 Pedro de Brizuela, aparejador de las Obras Reales de la ciudad de Segovia, sucede al mando en las obras de reparación realizando trazas en 1618. Idem. SUPRA. Casas y Sitios Reales, leg. 327, fols. 361-362-363 y 365.

${ }^{47}$ Idem, leg. 359. 


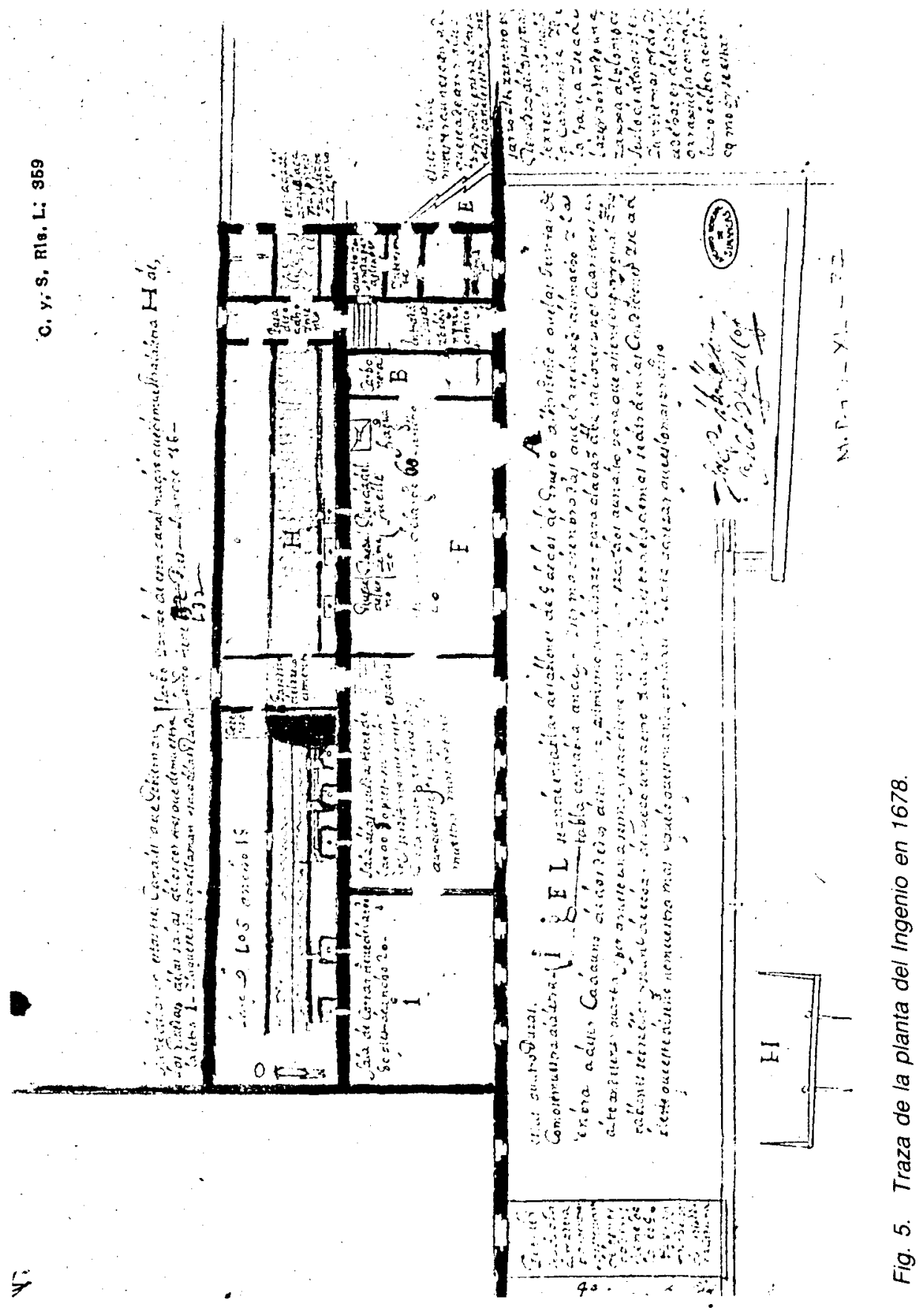


de 20 pies...". Estos datos permiten asegurar la ampliación de la fábrica si tenemos en cuenta los 150 pies de largo que contaba cuando Francisco de Ribera informaba en los momentos de la construcción.

Para salvar el desnivel de los patios se proyectó un «puente y pasadizo al cuarto de los mercaderes", citado en el plano y el documento, puente que volvería a ser construido posteriormente y en sucesivas reformas y del que todavía hoy se conservan restos. Asi mismo, se trazaron dos pasadizos «encima de las canales, el uno se pasa a la sala de recocimiento y el otro al Ingenio Chico". Dicho ingenio era una estancia situada frente al muro norte de la fábrica, al otro lado del canal, posiblemente en lo que se denominaba "cassa vieja" y en la que se acuñaba moneda de cobre siguiendo una técnica más tradicional. En cuanto a la sala de «recocimiento» nos preguntamos si no sería ésta la antigua fundición que en alzado presentaba una única planta y que Mora reformó tras el incendio de 1607. Pero la documentación sigue sin ser explícita.

La intervención en 1678 se incribe en unos momentos de aguda crisis monetaria. Durante el reinado de Carlos II la fábrica estuvo intermitentemente cerrada ${ }^{48}$, registrándose reformas importantes en $1690 \mathrm{y}$, con el cambio de siglo, en 1716 y años sucesivos ${ }^{49}$.

Ahora bien, el estado actual de la fábrica (fig. 6) revela que su crecimiento tuvo una planificación coherente, que muchos de los añadidos se centraron en el patio alto y que las numerosas reformas, como ya se ha señalado, tuvieron por objeto la puesta a punto de la zona relativa a los ingenios técnicos, sin afectar en exceso a la estructura arquitectónica. Pero ésta, si nos fijamos en la lámina, duplica en tamaño a quella que de 12 ventanas por piso indicaba en sus informes el veedor Francisco de Ribera. Evidentemente, al bloque herreriano se le añadió otra crujia, de idéntico estilo y alternancia de vanos. Entre ambos bloques existe una ligera desviación, explicable por la situación del canal, pegado al muro

48 Según el "Discurso sobre la Real Casa de Moneda de la ciudad de Segovia" en la última década del siglo XVII la fábrica funcionó. Biblioteca Nacional, Ms. 18.631-5.

${ }_{49}$ La información y datos sobre las habilitaciones de la fábrica para emitir moneda a lo largo del siglo XVIII resultan ya más dispersas. Además de los documentos de Simancas hay que contar con los que proporciona el Archivo Histórico Nacional. Según esto, entre 1740 y 1745 , el edificio vuelve a repararse y en 1752 un incendio obliga a realizar ctres proyectos que el Superintendente de esta Real Casa de la Moneda dirigió a la Real Junta sobre los reparos...", AHN, Sec. Estado, Leg. 2941. Los documentos relativos a la ceca segoviana en la Sección de Fondos Modernos, Hacienda-Casa Moneda, legs. 7.373, 7.375 y 7.827 


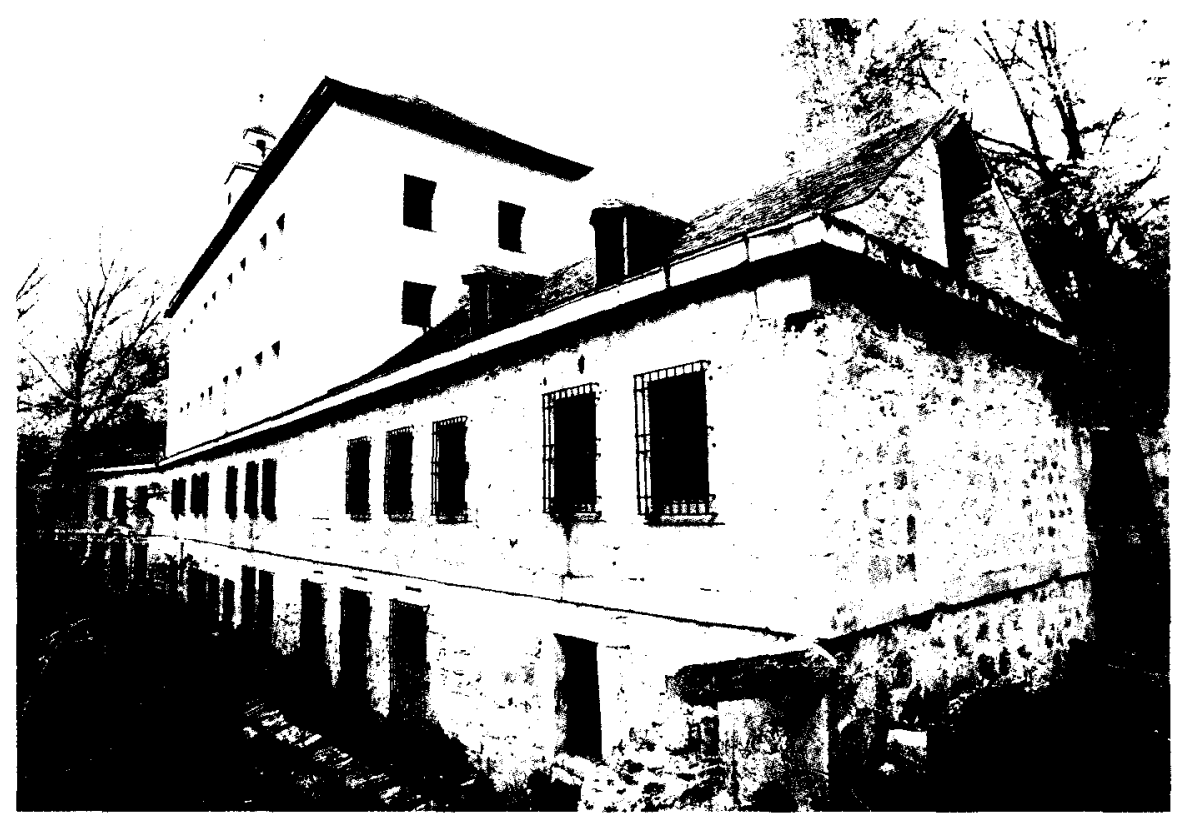

Fig. 6. Estado actual del edificio.

norte del primitivo edificio, y por la orilla del río Eresma, colindante a la nueva ampliación (fig. 7).

El problema se plantea al intentar datar este último bloque que en nada altera el carácter funcional y la sobriedad herreriana. No coincide además con ninguna de las dos trazas conservadas, ya que, como hemos referido, la primera revela la reconstrucción de una sala de fundición (fig. 4), independiente a la estructura primitiva - si nos atenemos a su alzado-, mientras que la segunda refleja la disposición de esta última, el denominado "ingenio", en 1678.

$\mathrm{Si}$ el nuevo bloque del poniente no corresponde a los informes que Ribera cumplia en los momentos de su construcción, la autoria deberia corresponder a Francisco de Mora y a "las obras modernas» que a partir de 1587 le adjudicaba Llaguno. Sin embargo, los avatares de este edificio fueron tantos que tal atribución no deja de ser una hipótesis más, susceptible de nuevas autorias en reformas sucesivas.

Con todo, hay detalles que inducen a pensar que algunos de los edificios del complejo fabril pertenecen, si no a los últimos años del 


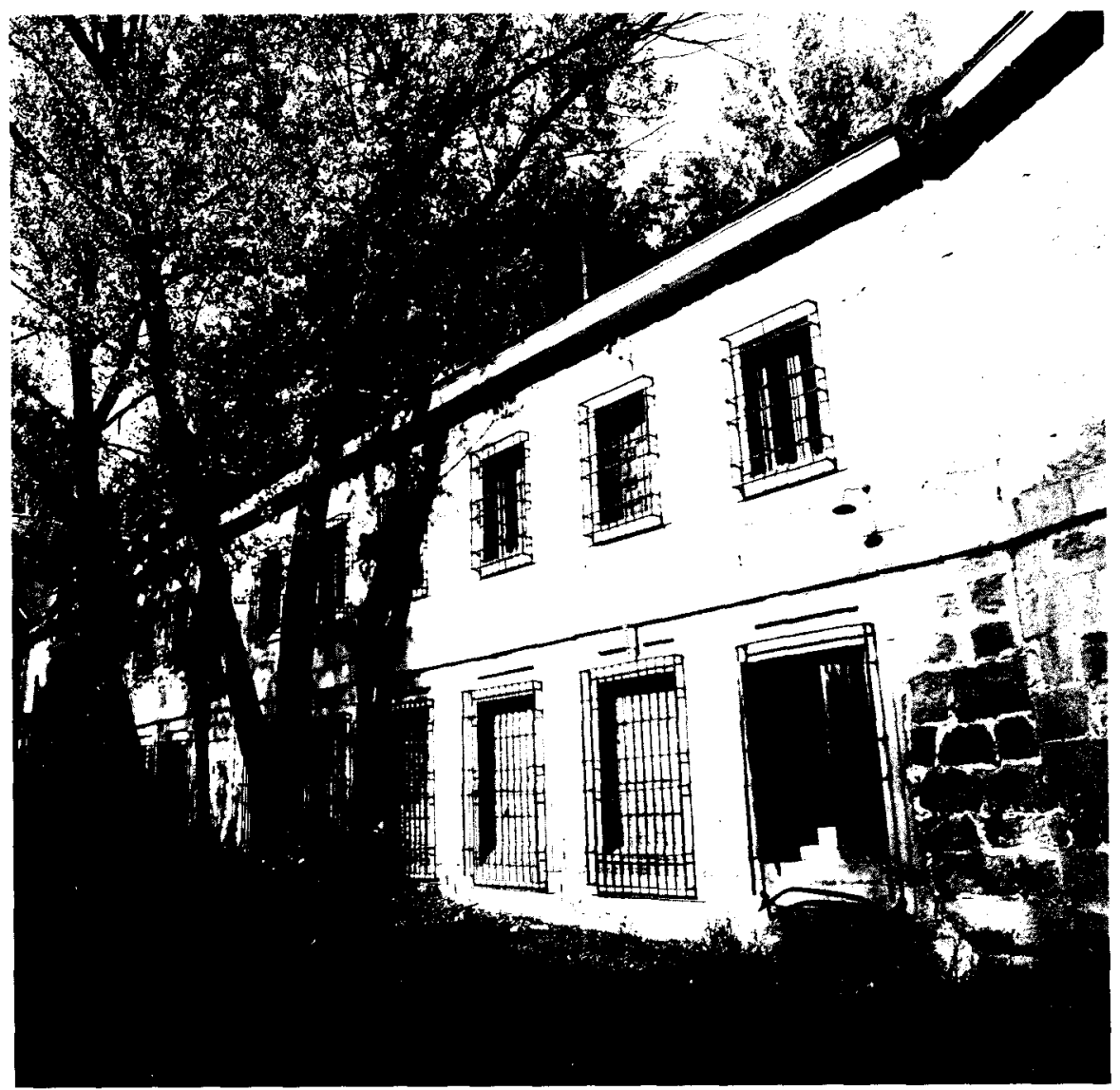

Fig. 7. Iramo occidental de la fábrica de la moneda.

siglo xVI, sí a unas fechas tempranas de la centuria siguiente. Por ejemplo, las terminaciones escalonadas de las cubiertas, de indudable influencia flamenca y típicos motivos de los palacetes y casas del reinado de Felipe II, aparecen no sólo en la fábrica herreriana, sino también en alguno de los edificios del denominado patio alto (fig. 8).

Una de las cuestiones anteriormente indicadas era la posible repercusión del proyecto de Herrera. Sin embargo, seria gratuito intentar establecer comparaciones con las fábricas existentes durante el siglo XVII, ya que muchas no utilizaron motriz hidráulica y seguían acuñando con sistemas tradicionales. La mayoría de las cecas continuaban ocupando 


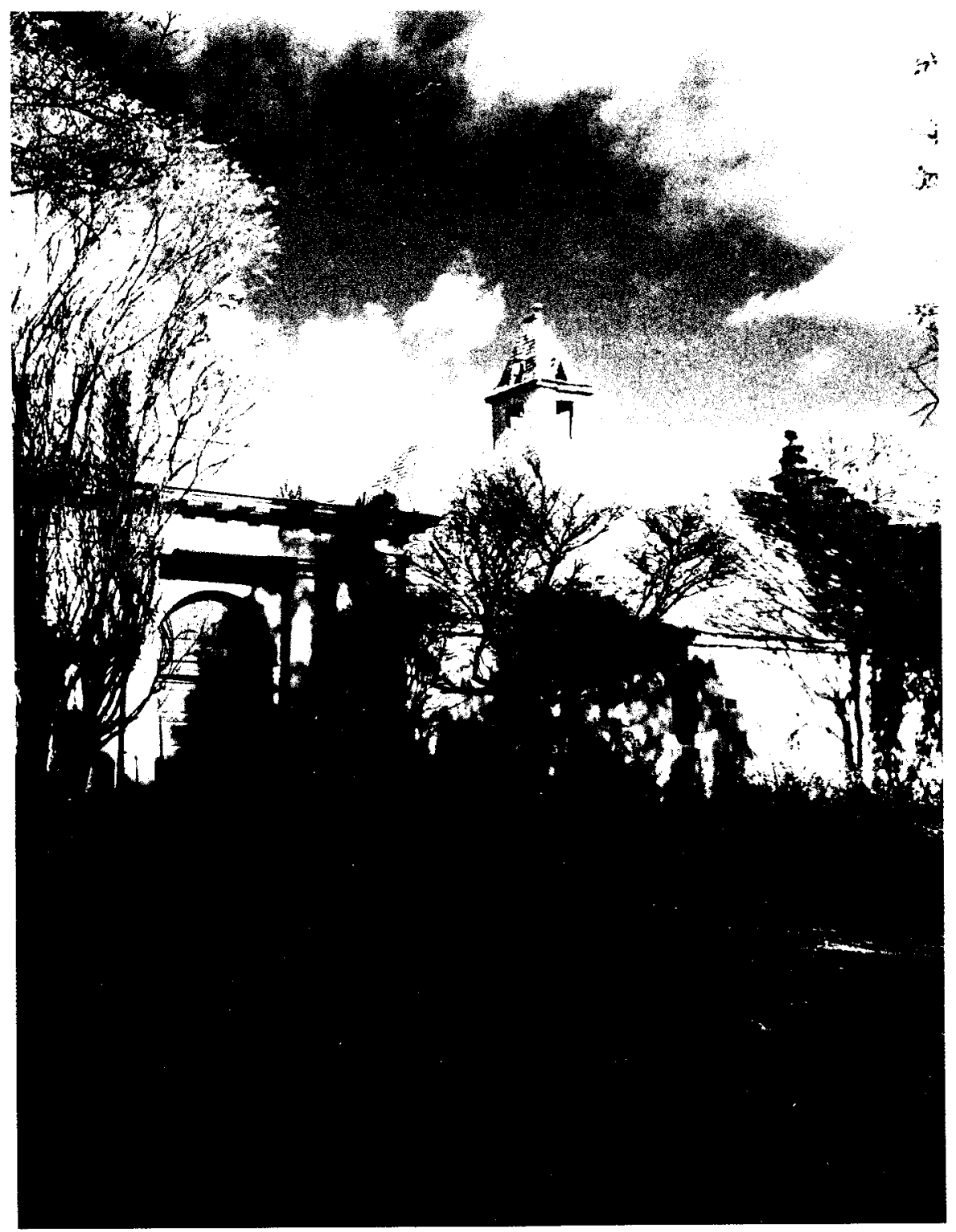

Fig. 8. Entrada principal al patio alto del Ingenio. 
los viejos solares, pero apenas se conoce su configuración. Como ocurrió con la fábrica de Segovia, el resto fueron objeto de numerosas reformas y ampliaciones, a merced de las primeras ordenanzas y según las necesidades políticas y económico-monetarias del momento.

Los escasos datos siempre mencionan "ser conforme a las leyes de estos reinos", contando con "quarto principal,..., sala de libranza y contaduría,..., sello real,..., hornos, aposentos de la talla y ornazas, ... aposento del ensayador..." ${ }^{50}$, etc... También la escasez de planos o dibujos impide una comprensión clara de la organización de aquellas estancias. Prueba de ello es un dato de interés sobre la casa de la moneda de La Coruña a comienzos del siglo XVII: se trata de un rasguño que refleja la planta del edificio sin leyenda alguna ${ }^{51}$ y en el que destacan cinco estancias y dos corredores que comunican con la principal. Por lo que se deduce, el edificio tenía una única entrada (fig. 9).

Dos fábricas de nueva planta se realizaron en el siglo XVII. En 1615 Felipe III expide una cédula para dotar a la Corte de una Casa de Moneda ${ }^{52}$, indicando en ella como debía ser la planta de los oficios. Se construyó en la calle de Segovia y empezó a funcionar en 1618. Aparece en el plano de Pedro de Texeira con el número 29 y muestra una construcción de crujias en torno a un patio central rectangular y una serie de casas que encerraban otros dos patios irregulares. Casi medio siglo después, Felipe IV ordena la construcción de una fábrica en Cuenca para sustituir la vieja ceca de la ciudad. Se ubicó a orillas del río Júcar, fuera del casco urbano, pues desde sus inicios contó con un «ingenio" hidráulico de acuñación. González Tascón al estudiar esta ceca indica que tenía planta rectangular y en su interior albergaba los ingenios de agua. Los planos del edificio revelan ya una indudable coherencia en la configuración interna, pero fueron realizados en plena segunda mitad del siglo XVIII cuando en este tipo de fábricas se ha operado una clara normalización tipológica a raíz del férreo control de los Borbones en las cecas de las colonias americanas, todas de nueva planta.

${ }^{50}$ Asi se mencionan las estancias de la Ceca de Burgos cuando los representantes de la ciudad hicieron una visita al citado edificio en 1651; documento publicado por A. Bartolomé y F. A. Sainz de Varona, ob. cit., pág. 12.

${ }^{51}$ Agradezco a Alicia Cámara el que me haya proporcionado este documento del Archivo General de Simancas (Guerra Antigua, leg. 597). Lleva la fecha de 18 de noviembre de 1603 .

${ }_{52}$ Rivero, Casto María del, "Origenes de la Ceca de Madrid" en Revista de la Biblioteca, Archivo y Museo del Ayuntamiento de Madrid, Año I, abril 1924, núm 2, págs. 129137. 


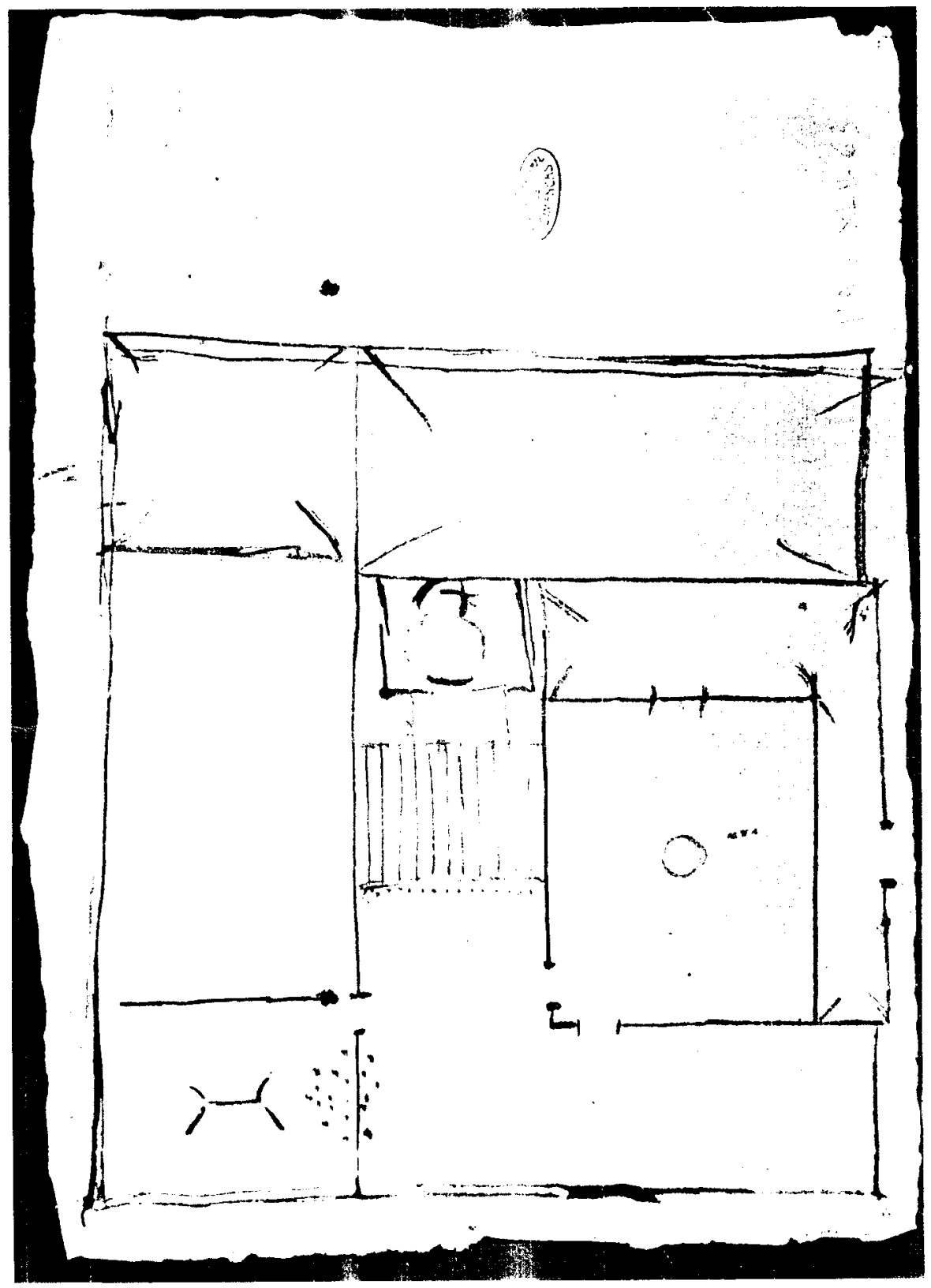

Fig. 9. Rasguño de la planta de la ceca de La Coruña. 
De ahi que haya que subrayar la excepcionalidad de la obra de Herrera en Segovia como ejemplo aislado en el panorama arquitectónico del siglo $\mathrm{xv}_{1}{ }^{53}$. Ni el ejemplo de este arquitecto ni las normas legales parecen haber influido lo más mínimo en aquella normalización arquitectónica y es que esta tipología fabril no pudo fraguar en España tras el corto periodo de renovación técnica que existió con Felipe II.

${ }^{53}$ El edificio en la actualidad se encuentra en compieto abandono y requiere una inmediata intervención. Las fotografías que ilustran el presente artículo proceden del archivo fotográfico del arquitecto Javier Feduchi, a quien quiero expresar mi agradecimiento, asi como a Gleen S. Murray y a los encargados de la Biblioteca de la Casa de la Moneda por haberme facilitado la documentación pertinente, todos ellos preocupados por el decadente estado de esta joya arquitectónica. 
